\title{
Single flash electroretinograms of mature cataractous and fellow eyes
}

\author{
This article was published in the following Dove Press journal: \\ Clinical Ophthalmology \\ 17 October 2016 \\ Number of times this article has been viewed
}

\section{Yasuyuki Yamauchi' \\ Jun-ichi Mochizuki' \\ Akito Hirakata ${ }^{2}$ \\ Shigekazu Uda'}

'Nihonmatsu Eye Hospital, Edogawa, Tokyo, Japan; ${ }^{2}$ Kyorin Eye Center, Kyorin University School of Medicine, Tokyo, Japan
Correspondence: Yasuyuki Yamauchi TI32-0035 Nihonmatsu Eye Hospital, Hirai 4-10-7 Edogawa-ku, Tokyo, Japan

Tel $+8|3368| \quad 257$

Fax +8I 35609 I648

Email phthisis@nifty.com
Background: It is generally stated that opacities of the ocular media, including senile cataract, have little effect on the electrical responses of the retina. However, lower amplitudes and longer implicit times are sometimes observed in electroretinograms (ERGs) of patients with mature cataract.

Methods: Single flash ERGs of mature cataractous eyes with decimal visual acuity less than 0.1 were compared with those of the fellow eyes with decimal visual acuity better than 0.5 , in 105 senile cataract patients.

Results: The mean amplitudes and implicit times of ERG a-waves were, respectively, 323.6 $\pm 95.8 \mu \mathrm{V}$ and $14.7 \pm 3.5 \mathrm{~ms}$ in the cataractous eyes and $352.3 \pm 96.6 \mu \mathrm{V}$ and $12.0 \pm 1.5 \mathrm{~ms}$ in the fellow eyes. The mean amplitudes and implicit times of ERG b-waves were, respectively, $390.1 \pm 108.7 \mu \mathrm{V}$ and $63.4 \pm 27.9 \mathrm{~ms}$ in the cataractous eyes and $415.3 \pm 119.1 \mu \mathrm{V}$ and $59.0 \pm 9.3 \mathrm{~ms}$ in the fellow eyes. The mean amplitudes of the $a-$ and $b$-waves were significantly lower and the mean implicit times of the a- and b-wave were significantly longer in the cataractous eyes as compared to those of the fellow eyes. Postoperative visual acuity was similar in cataractous and fellow eyes.

Conclusion: Even though single flash ERG was influenced due to mature cataract, eyes revealed good postoperative visual acuity. Single flash ERG does not always reflect the foveal function and the visual pathway; nevertheless, it remains a reliable guide to evaluate visual prognosis before cataract surgery.

Keywords: single flash ERG, mature cataract

\section{Introduction}

It is generally stated that opacities of the ocular media, including senile cataract, have little effect on the electrical responses of the retina. ${ }^{1,2}$ Single flash electroretinogram (ERG) has been widely used, as a commercially available technology, to examine retinal function prior to cataract surgery, especially when the opacity is so severe that visual acuity (VA) of the patient is extremely poor and fundus condition is not visible. In a previous study with 22 patients with mature cataract, it was observed that single flash ERG values decreased depending on the degree of cataract opacity, even though the difference was not significant ${ }^{3}$ and Uji showed that the amplitude of ERG b-wave was significantly increased after cataract surgery in comparison to the preoperative result. ${ }^{4}$ An et al showed that the amplitude of central point multifocal ERG was significantly lower in cataract patients compared with control group, from "hand movement" (HM) to 0.8 of preoperative VA. ${ }^{5}$ Furthermore, Miura et al reported that the presence of cataracts of Grade 2 or higher affect the amplitude and the implicit time of flicker ERGs. ${ }^{6}$ However, ERG information in patients with mature cataract is still limited. The goal of this study was to examine whether single flash ERG was different between cataractous and fellow eyes in patients with severe cataract.

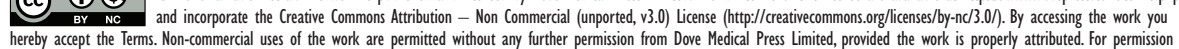
for commercial use of this work, please see paragraphs 4.2 and 5 of our Terms (https://www.dovepress.com/terms.php). 


\section{Methods}

\section{Subjects}

A total of 117 patients with a mature cataractous eye was included in this study.

The first group comprised 105 patients with a mature

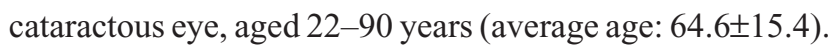
These patients underwent surgery in the period between September 2011 and November 2015, at Nihonmatsu Eye Hospital, Tokyo, Japan. The decimal VA of cataractous eyes was in the range from "light perception" (LP) to 0.1 . The cataractous and fellow eyes did not have any ophthalmic diseases other than cataract. All fellow eyes had a VA higher than 0.5 , with average of $0.86 \pm 0.27$. All cataractous and fellow eyes received an examination that included slit lamp and indirect ophthalmoscope, before and after cataract surgery. However, fundus condition was invisible before surgery in mature cataractous eyes. Cataract surgeries were performed in cataractous eyes of 103 subjects by phacoemulsification with posterior chamber intraocular foldable hydrophobic acrylic lens implantation. Extracapsular cataract extraction and implantation of a sulcus-sutured polymethyl methacrylate lens were performed in 2 subjects. No operative complications were registered.

The second group, comprising 12 subjects aged 53-87 years (average age: 72.2 \pm 8.7 ) with mature cataract in both eyes and VA less than 0.1 who revealed good VA in both eyes after cataract surgery were used to investigate whether ERG differed between severe cataractous eyes. In this group, if the VA was equal, the eye showing less opacity in slit lamp examination was chosen as the fellow eye.

The experimental procedures were approved by the Medical Ethics Committee of the Nihonmatsu Eye Hospital, Tokyo, Japan. Informed consent was obtained from all participants. This research was conducted in accordance with the institutional guidelines and the tenets of the Declaration of Helsinki.

\section{VA test}

A Snellen chart was used to test the best-corrected VA of mature cataractous eyes and fellow eyes, whenever a cataract surgery was performed in the latter, before and after cataract surgery. The chart was viewed at a distance of $5 \mathrm{~m}$, and VA was based on the smallest line that could be read. When patients could not see any of the characters for VA 0.1 at $5 \mathrm{~m}$, VA was measured at $4 \mathrm{~m}, 3 \mathrm{~m}, 2 \mathrm{~m}$, or $1 \mathrm{~m}$ and calculated by the formula:

$$
\mathrm{VA}=0.1 \times \text { distance } / 5
$$

When patients could not see the character at less than $1 \mathrm{~m}$, VA was measured by the counting fingers, HM, or LP tests at a distance of $30 \mathrm{~cm}$. In this study, for the statistical analysis, HM and counting fingers were considered as 0.005 and LP as 0.001. Statistical analysis of the VA was calculated after conversion to logarithm of the minimum angle of resolution units.

\section{ERG recordings}

The subjects' pupils were maximally dilated with $0.5 \%$ tropicamide and $2.5 \%$ phenylephrine hydrochloride for all ERG recordings. ERG recording was not started until the pupils were dilated to, at least, $7 \mathrm{~mm}$ in diameter. After inducing anesthesia with 1 drop of $0.4 \%$ oxybuprocaine hydrochloride, the white light emitting diode electrode was placed on the cornea. A reference electrode was placed on the cheek, and a ground electrode was placed on the earlobe. ERG was recorded using white-flash stimulus (maximal combined response) after 10 minutes of dark adaptation. A commercial system (LE-4000, TOMEY corporation, Nagoya, Japan) was used to measure ERG with a 0.3 to $340 \mathrm{~Hz}$ band-pass filter, stimulation luminance set at $200 \mathrm{~cd} \cdot \mathrm{s} \cdot \mathrm{m}^{-2}$ $\left(20,000 \mathrm{~cd} \cdot \mathrm{m}^{-2} \times 10 \mathrm{~ms}\right)$. Recordings were not averaged.

\section{Statistical analysis}

Normality tests (Kolmogorov-Smirnov test and ShapiroWilk normality test) were conducted. If the data was not nonnormal $(P \geq 0.05)$ in both normality tests, paired $t$-test was used. On the other hand, when the data was nonnormal $(P<0.05)$ in a normality test, Wilcoxon's signed rank test was used.

Paired $t$-test was used to compare amplitudes of ERGs in the first and second groups between cataractous and fellow eyes. Wilcoxon's signed rank test was used to compare implicit times of ERGs in the first and second groups and VA in the first group, between cataractous and fellow eyes. The data are presented as the mean \pm standard deviation. Significance was accepted for $P<0.05$. Data were statistically analyzed using Excel 2010 (paired $t$-test) and Eazy R software (Kolmogorov-Smirnov test, Shapiro-Wilk normality test and Wilcoxon's signed rank test).

\section{Results \\ First group}

The mean VA of cataractous and fellow eyes was, respectively, $0.0067 \pm 0.02$ and $0.86 \pm 0.27$ before surgery and $1.0 \pm 0.23$ and $1.0 \pm 0.20$ after surgery (Table 1 ). VA before and after surgery was nonnormal in the normality tests. 
Table I Decimal visual acuity of group I

\begin{tabular}{|c|c|c|c|c|}
\hline & \multicolumn{2}{|c|}{ Before surgery } & \multicolumn{2}{|l|}{ After surgery } \\
\hline & $\begin{array}{l}\text { Cataractous } \\
\text { eyes }\end{array}$ & $\begin{array}{l}\text { Fellow } \\
\text { eyes }\end{array}$ & $\begin{array}{l}\text { Cataractous } \\
\text { eyes }\end{array}$ & $\begin{array}{l}\text { Fellow } \\
\text { eyes }\end{array}$ \\
\hline $\mathrm{mal}$ & $0.0067 \pm 0.02$ & $0.86 \pm 0.27$ & $1.0 \pm 0.23$ & $1.0 \pm 0.20$ \\
\hline
\end{tabular}

visual acuity

Notes: Data presented as mean \pm standard deviation, $" P<0.0001, n=105$. Mean decimal visual acuity before and after surgery was analyzed with Wilcoxon's signed rank test.

The difference was significant before surgery but not after surgery in the Wilcoxon's signed rank test.

The mean amplitudes and implicit times of ERG a-waves were, respectively, $323.6 \pm 95.8 \mu \mathrm{V}$ and $14.7 \pm 3.5 \mathrm{~ms}$ in the cataractous eyes and $352.3 \pm 96.6 \mu \mathrm{V}$ and $12.0 \pm 1.5 \mathrm{~ms}$ in the fellow eyes. The mean amplitudes and implicit times of ERG b-waves were, respectively, 390.1 $108.7 \mu \mathrm{V}$ and $63.4 \pm 27.9 \mathrm{~ms}$ in the cataractous eyes and $415.3 \pm 119.1 \mu \mathrm{V}$ and $59.0 \pm 9.3 \mathrm{~ms}$ in the fellow eyes. The amplitudes of aand $b$-waves in the cataractous eyes and fellow eyes were not nonnormal in the normality tests. The implicit times of $a-$ and b-waves in the cataractous eyes and fellow eyes were nonnormal in the normality tests. The mean amplitudes of the a- and b-waves were significantly reduced (paired $t$-test) and the mean implicit time of the a- and b-wave was significantly longer (Wilcoxon's signed rank test) in the cataractous eyes in comparison with the fellow eyes (Table 2).

Of the 105 subjects, 15 subjects revealed negative pattern ERG ( 3 of them showed only in the cataractous eye) but no abnormalities, including chorioretinal atrophy with myopia, were found with indirect ophthalmoscopy. In addition, in 20 out of 105 subjects, the amplitude of both ERG a- and $\mathrm{b}$-wave was higher in the mature cataractous eye than in the fellow eye. Of the 20 subjects, 2 subjects had supernormal (more than the mean $+1.64 *$ standard deviation of the fellow eyes of 105 subjects; $90 \%$ confidence interval) amplitude of ERG a-wave and 1 subject showed supernormal amplitude of ERG b-wave in mature cataractous eye. Four subjects

Table 2 Electroretinogram (ERG) recordings of group I

\begin{tabular}{lll}
\hline & ERG recordings \\
\cline { 2 - 3 } & Cataractous eyes & Fellow eyes \\
\hline Mean amplitude of a-wave & $323.6 \pm 95.8 \mu \mathrm{V}^{\circ}$ & $352.3 \pm 96.6 \mu \mathrm{V}^{\circ}$ \\
Mean amplitude of b-wave & $390.1 \pm 108.7 \mu \mathrm{V}^{\mathbf{\Delta}}$ & $415.3 \pm 119.1 \mu \mathrm{V}^{\mathbf{}}$ \\
Mean implicit time of a-wave & $14.7 \pm 3.5 \mathrm{~ms}^{\diamond}$ & $12.0 \pm 1.5 \mathrm{~ms}^{\diamond}$ \\
Mean implicit time of b-wave & $63.4 \pm 27.9 \mathrm{~ms}^{\mathbf{\Delta}}$ & $59.0 \pm 9.3 \mathrm{~ms}^{\mathbf{\Delta}}$ \\
\hline
\end{tabular}

Notes: Data presented as mean \pm standard deviation. ${ }^{\circ} P<0.0005, \Delta P<0.005$, ${ }^{\wedge}<0.000 \mathrm{I}, \mathrm{n}=105$. Mean amplitude of a-wave and mean amplitude of $\mathrm{b}$-wave were analyzed with paired $t$-test. Mean implicit time of a-wave and mean implicit time of b-wave were analyzed with Wilcoxon's signed rank test.
Table 3 Electroretinogram recordings of group 2

\begin{tabular}{lll}
\hline & Cataractous eyes & Fellow eyes \\
\hline Mean amplitude of a-wave & $292.5 \pm 81.4 \mu \mathrm{V}$ & $287.8 \pm 74.3 \mu \mathrm{V}$ \\
Mean amplitude of b-wave & $396.5 \pm 125.2 \mu \mathrm{V}$ & $340.4 \pm 118.9 \mu \mathrm{V}$ \\
Mean implicit time of a-wave & $17.0 \pm 3.9 \mathrm{~ms}$ & $14.9 \pm 1.7 \mathrm{~ms}$ \\
Mean implicit time of b-wave & $65.1 \pm 9.6 \mathrm{~ms}$ & $63.0 \pm 11.4 \mathrm{~ms}$ \\
\hline
\end{tabular}

Notes: Data presented as mean \pm standard deviation. No statistically significant differences were found between cataractous eyes and fellow eyes, $n=12$. Mean amplitude of a-wave and mean amplitude of b-wave were analyzed with paired $t$-test. Mean implicit time of a-wave and mean implicit time of b-wave were analyzed with Wilcoxon's signed rank test.

revealed supernormal amplitude of ERG a-wave and 7 subjects had supernormal amplitude of ERG b-wave in the fellow eye of 105 subjects in the first group.

\section{Second group}

The mean amplitude and the mean implicit time of ERG a-waves were, respectively, $292.5 \pm 81.4 \mu \mathrm{V}$ and $17.0 \pm 3.9 \mathrm{~ms}$ in cataractous eyes and $287.8 \pm 74.3 \mu \mathrm{V}$ and $14.9 \pm 1.7 \mathrm{~ms}$ in fellow eyes. The mean amplitude and the mean implicit time of ERG b-waves were, respectively, $396.5 \pm 125.2 \mu \mathrm{V}$ and $65.1 \pm 9.6 \mathrm{~ms}$ in cataractous eyes and $340.4 \pm 118.9 \mu \mathrm{V}$ and $63.0 \pm 10.2 \mathrm{~ms}$ in fellow eyes (Table 3 ).

The amplitudes of a- and b-waves in the cataractous eyes and fellow eyes were not nonnormal in the normality tests. The implicit times of a- and b-waves in the cataractous eyes and fellow eyes were nonnormal in the normality tests.

No statistically significant differences were found between cataractous eyes and fellow eyes in the ERG.

\section{Discussion}

In this study, the mean amplitudes of ERG a- and b-waves were statistically lower in mature cataractous eyes than in fellow eyes, which may be due to the light-absorbing effect of the cataract. In fact, in group 2, in which the degree of opacity of cataract did not vary, ERG was not different between both mature cataractous eyes. However, in 20 out of 105 subjects, the amplitude of both ERG a- and b-wave was higher in mature cataractous eyes than in fellow eyes. Therefore, our data do not support that all mature cataractous eyes will show reduced values in ERGs. Of the 20 subjects, 2 subjects had supernormal amplitude of ERG a-wave and 1 subject showed supernormal amplitude of ERG b-wave in mature cataractous eyes. Even though, opacities of cataractous eyes in the slit lamp examination seemed to be severe enough to absorb the stimulation flash light. At the moment, we do not have enough evidence to speculate.

On the other hand, 4 subjects revealed supernormal amplitude of ERG a-wave and 7 subjects had supernormal 
amplitude of ERG b-wave in fellow eyes of 105 subjects in the first group.

ERG is affected by age. However, in this study, we compared cataractous eyes and fellow eyes in patients. Thus, we thought the influence due to age was limited.

The stimulus luminance in this study was $200 \mathrm{~cd} \cdot \mathrm{s} \cdot \mathrm{m}^{-2}$, 10 times greater than that recommended by the International Society for Clinical Electrophysiology of Vision. ${ }^{7}$ Thus, stimulus luminance was probably strong enough to record a single flash ERG of eyes with opacities of optic media.

In recent studies, Miura et al mentioned that the presence of cataracts should be taken into consideration when interpreting flicker ERGs, ${ }^{6}$ and An et al showed that the amplitude of central point multifocal ERG was significantly lower in cataract patients. ${ }^{5}$ However, Cruz and Adachi-Usami observed that, in a single flash ERG, the mean amplitudes of the a- and b-waves were slightly reduced in the mature cataractous eyes as compared to those of the fellow eyes, but the difference was not significant. ${ }^{3}$ In our study, the lightabsorbing effect of the cataract, based on the amplitudes of a- and b-waves, was approximately $8 \%$ and $6 \%$, respectively, instead of the $0.5 \mathrm{log}$ unit observed by them. We followed a method of analysis similar to that used by Cruz and AdachiUsami. ${ }^{3}$ Unfortunately, their study included only 22 subjects, while ours comprised 105 . If they had more subjects in the analysis, a statistical difference between cataractous and fellow eyes might have been obtained.

Chorioretinal atrophy was the most common cause of subnormal ERGs. Postoperative VA was shown to be lower in cataractous eyes with subnormal ERGs than in eyes with normal ERGs. ${ }^{3}$ In our study, 15 out of 105 subjects with negative pattern ERG and good VA after cataract surgery did not show any obvious fundus abnormalities, including chorioretinal atrophy.

Algvere et al stated that preoperative flash ERG and visually evoked cortical potential are not able to safely predict the outcome of vitrectomy in diabetics with very low VA. ${ }^{8}$ According to our data, even if the retinal function is normal, a single flash ERG result can be decreased by opacity of the ocular media (mature cataract). Therefore, evaluation of visual function with flash ERG of a patient with plural media opacities (corneal opacities, cataract, vitreous hemorrhage, etc.) would be much more difficult.

\section{Conclusion}

In conclusion, severe cataract can reduce the amplitude and increase the implicit time of single flash ERG a- and b-waves, in eyes with good visual function.

\section{Acknowledgments}

We thank EDITAGE for the professional editing and colleagues of Nihonmatsu Eye Hospital for their efforts and time donated to the study.

\section{Disclosure}

The authors report no conflicts of interest in this work.

\section{References}

1. Burian HM, Burns CA. A note on senile cataracts and the electroretinogram. Doc Ophthalmol. 1966;20:141-149.

2. van Lith GH. Application of electro-ophthalmology. In: Michaelson IC, editor. Textbook of the Fundus of the Eye. 3rd ed. Great Britain: Clark Constable Ltd; 1980:627-632.

3. Cruz RD, Adachi-Usami E. Quantitative evaluation of electroretinogram before cataract surgery. Jpn J Ophthalmol. 1989;33(4):451-457.

4. Uji Y. [The effects of absorption of visible light in the human lens on the electroretinography. 2. Comparison of the spectral ERGs recorded before and after cataract surgery (author's transl)]. Nippon Ganka Gakkai Zasshi. 1977;81(9):1321-1327. Japanese.

5. An J, Zhang L, Wang Y, Zhang Z. The success of cataract surgery and the preoperative measurement of retinal function by electrophysiological techniques. J Ophthalmol. 2015;2015:401281. Epub 2015 Oct 21.

6. Miura G, Nakamura Y, Sato E, Yamamoto S. Effects of cataracts on flicker electroretinograms recorded with RETeval ${ }^{\mathrm{TM}}$ system: new mydriasis-free ERG device. BMC Ophthalmol. 2016;16:22.

7. McCulloch DL, Marmor MF, Brigell MG, et al. ISCEV Standard for full-field clinical electroretinography (2015 update). Doc Ophthalmol. 2015;130(1):1-12.

8. Algvere P, Persson HE, Wanger P. Preoperative electroretinograms and visual evoked cortical potentials for predicting outcome of vitrectomy in diabetics. Retina. 1985;5(3):179-183.
Clinical Ophthalmology

\section{Publish your work in this journal}

Clinical Ophthalmology is an international, peer-reviewed journal covering all subspecialties within ophthalmology. Key topics include: Optometry; Visual science; Pharmacology and drug therapy in eye diseases; Basic Sciences; Primary and Secondary eye care; Patient Safety and Quality of Care Improvements. This journal is indexed on Submit your manuscript here: http://www.dovepress.com/clinical-ophthalmology-journal

\section{Dovepress}

PubMed Central and CAS, and is the official journal of The Society of Clinical Ophthalmology (SCO). The manuscript management system is completely online and includes a very quick and fair peer-review system, which is all easy to use. Visit http://www.dovepress.com/ testimonials.php to read real quotes from published authors. 